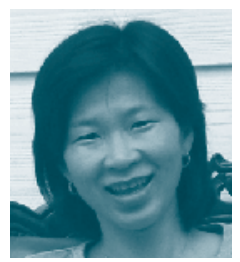

Linda Rykkje Sykepleier/Cand.san, stipendiat ved Høgskolen Stord/Haugesund

\title{
$\mathrm{Gi}$ eldre en verdig død
}

\author{
Palliativ behandling spesielt rettet mot eldre mennesker er et økende behov.
}

A ntallet eldre i befolkningen øker raskt i de fleste land i verden. I Norge forventes en særlig økning fra 2010 når de store etterkrigskullene blir pensjonister. Andelen eldre over 67 år i befolkningen er vel 13 prosent. Denne forventes å stige til 19 prosent i 2030 og 22 prosent i 2050 (1). Endringer i familiestrukturer og befolkningssammensetning, særlig i vestlige land, medfører ifølge WHO en rekke helsepolitiske, økonomiske og etiske utfordringer i eldreomsorgen (2). På tross av velferdstilbud til eldre, hevder WHO at eldres behov i sluttfasen av livet ikke blir ivaretatt godt nok. Palliativ omsorg sørger for best mulig aktivitet og livskvalitet for pasienten inntil døden inntreffer. Et vesentlig prinsipp er at hjelpetiltakene verken skal bidra til å fremskynde eller utsettes avslutning av livet.

\section{Eldre forsømmes}

På tross av at et stadig økende antall mennesker opplever å bli mer enn 80 år, er likevel palliasjon i eldreomsorgen et forsømt område i de fleste land (3). I Norge tilbys palliasjon pasienter med uhelbredelig sykdom og kort forventet levetid og er hovedsakelig rettet mot kreftlidelser (4). Erfaringen fra kreftpasienter kan overføres til andre sykdomstilstander ved en terminalfase (5). Men palliativ medisin med utspring i kreftbehandling er ikke nødvendigvis anvendbar for eldre pasienter. De eldre har gjerne et forløp med flere kritiske sykdomsepisoder slik at tidspunktet for når døden er forventet er vanskeligere å forutse enn ved kreftlidelser (6).

\section{Nytt fagfelt}

Palliasjon som fagfelt er forholdsvis nytt, og det trengs mer forskning på området i Norge og internasjonalt (7). Det har imidlertid lenge eksistert hospice ved sykehus for å ivareta kreftpasienter i sluttfasen av livet (8). Men hospice er lite egnet for skrøpelige gamle, som ofte har en gradvis og langsom progresjon i tap av helse og funksjonssvikt før døden inntreffer (9). Ved opprettelsen av en norsk standard for palliasjon (10) er det laget rammer for at palliasjon også tilbys i hjemmebaserte tjenester og i sykehjem. Standarden beskriver palliasjon som mer enn behandling og pleie av døende, og anses for å være en del av den integrerte behandlingskjeden for alle mennesker med uhelbredelig sykdom. Således har palliasjon mulighet for å bli et godt tilbud også til skrøpelige gamle mennesker. Utfordringen er å få dette iverksatt i sykehjem og hjemmetjenester.

\section{Generelle utfordringer}

Det er annerledes å dø gammel enn å dø ung, derfor må fagfeltet palliasjon tilpasses geriatriske pasienter (11). Særlig viktig er det å forstå at symptompresentasjonen endrer seg ved alderen. Helsepersonell kan misforstå eller unngå å fange opp subtile symptomendringer hos eldre som indikerer forverring av eksisterende sykdom eller akutt sykdom. Dette oppstår særlig fordi mental funksjon kan være endret, noe som kan skyldes senil demens, overmedisinering, cerebrovaskulær sykdom, hjertesykdom, infeksjoner, dårlig regulert blodsukker, ubehandlet thyroidose, vitaminmangel og så videre. Symptomer helsepersonell bør kartlegge er smerter, forvirring, dyspnø og fatigue, nedsatt appetitt og vekttap, gastrointestinale plager, infeksjoner, samt angst og depresjon (11).

\section{Smertelindring}

Smertelindring, samt ernæring- og væskebehandling i livets sluttfase er aktuelle problemstillinger for de fleste pasienter, og dette er særlig utfordrende i eldreomsorgen. Smerte er en subjektiv opplevelse, derfor er kartlegging av pasientens egen oppfatning viktig (12). Her kan en anvende ESAS-skjema (Edmont Symptom Assessment System) (13). Smerter hos palliative pasienter har mange dimensjoner, foruten det fysiske påvirkes pasienten også psykisk, åndelig og sosialt. De fysiske smertene kan forverres dersom pasienten sliter psykisk, og det er ikke god smertelindring å erstatte mangel på oppmerksomhet med medikamenter (14). Det er imidlertid viktig å tilby adekvat smertelindring, da smerter kan hindre pasientene fra å bearbeide andre, psykiske, sosiale eller åndelige, behov (15). Ved smertebehandling hos eldre i sluttfasen av livet bør en ordinere lave doseringer fordi eldre ofte har redusert toleranse for analgetika. Flere klarer seg med peroral eller supp administrering av kombinasjonsanalgetika eller forsiktig dosering av morfin peroralt eller subkutant (14). En stor utfordring i eldreomsorgen er smertelindring hos pasienter med demens, her er det imidlertid i senere tid utviklet kartleggingsskjema for bruk av pleiepersonell (16). En amerikansk studie viser at eldre personer med 


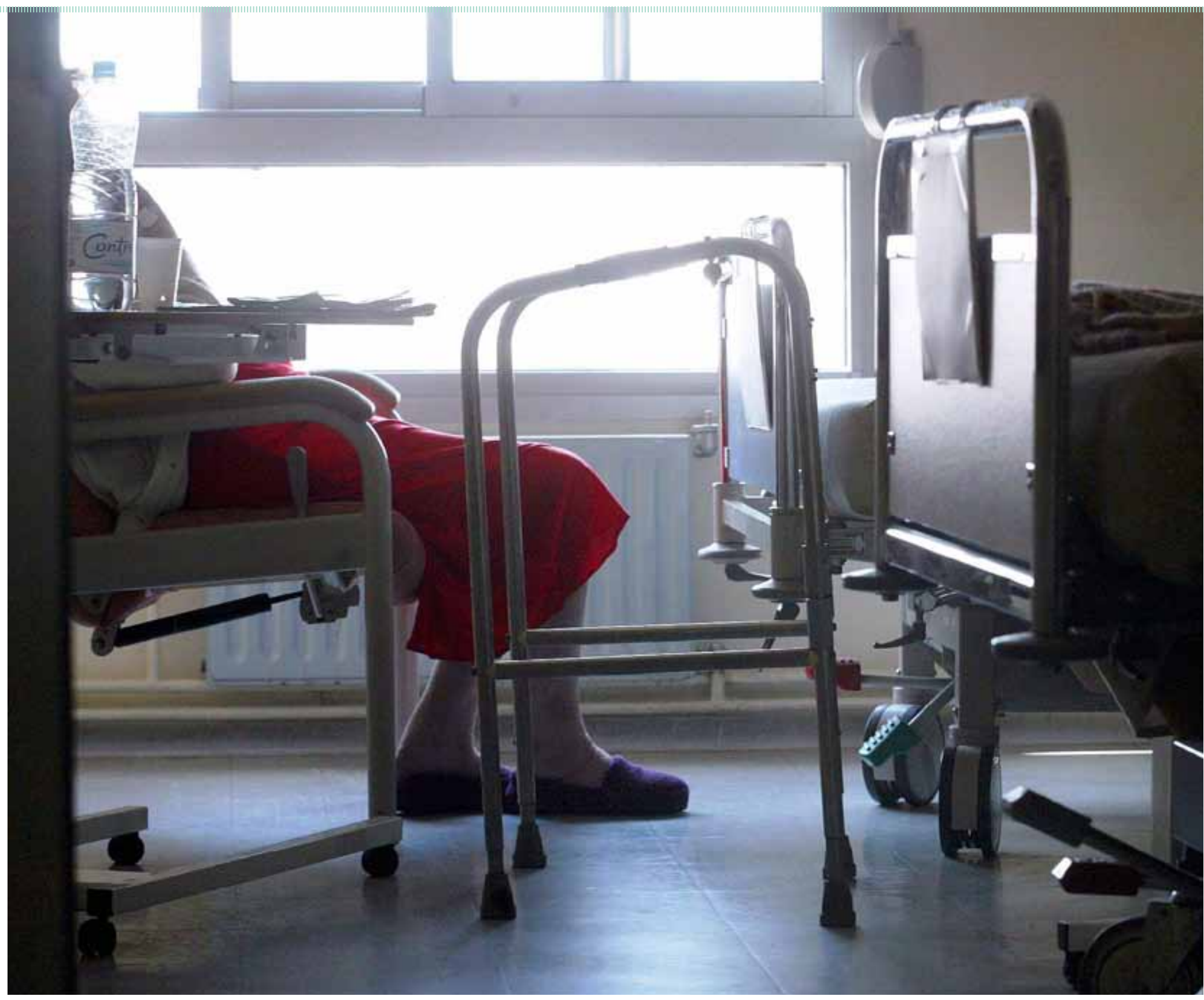

MANGLER KUNNSKAP: Det er mangel på kompetanse i palliativ omsorg rettet mot eldre mennesker både på sykehus, i sykehjem og hjemmetjenesten. Foto: Colourbox.

demens som dør i sykehjem ikke mottar den samme lindring av symptomer som terminale kreftpasienter (17). Smertelindring hos demenspasienter synes generelt å være et forsømt område som bør forbedres også i Norge.

\section{Ernæring}

Spørsmål om ernæring- og væskebehandling kan være utfordrende i sluttfasen av livet. Underernæring er vanlig blant eldre pasienter og blir sjelden behandlet ved innleggelse i sykehus (18). Det er derfor trolig generelt for lav grad av ernæringstiltak rettet mot eldres behov. Hos pasienter som ikke klarer å opprettholde tilstrekkelig næringsinntak kan NGS (nasogastrisk sonde) eller PEG (perkutan endoskopisk gastrostomi) være aktuelt. Men dette skal overveies nøye da studier viser at sondeernæring hos pasienter med omfattende komorbiditet og dårlig prognose, som skyldes andre årsaker enn underernæring, ikke har livsforlengende betydning (19). Det er vanskelig å avgjøre når det er riktig å avstå fra slik behandling. Derfor er det viktig at helsepersonell har gode etiske retningslinjer å støtte seg til for å møte slike utfordringer $(20,21)$.

Ved livets slutt er det normalt at interessen for mat og drik-

\section{Palliativ medisin med utspring $i$ kreftbe- handling er ikke nødvendigvis anvendbar for eldre pasienter.}

ke gradvis avtar. Utfordringen for sykepleiere er å avgjøre om det skal igangsettes kunstig ernæring eller andre ernæringstiltak, og når slike tiltak skal avsluttes. Sykepleieres holdninger til og kunnskaper om ernæringstiltak og væsketerapi varierer (22). Det er gjort få sykepleiestudier på området. En nederlandsk studie viser at å avstå fra kunstig ernæring hos pasienter med framskreden demens som spiser og drikker lite, ikke er forbundet med høy grad av ubehag hos pasientene (23). Når det gjelder infusjonsterapi og kunstig ernæring til døende pasienter viser litteraturen at dette ikke lindrer tørste, men tvert imot kan infusjon eller sondemat forverre problemene for pasienten ved $ø$ kt sekretproduksjon, lungeødem, kateterbehov og forlengelse av dødsprosessen (14). Hovedårsaken til tørste er tørre lepper, 
munn og svelg. Godt munnstell og hyppig fukting av munnhule er det viktigste vi kan gjøre for døende.

\section{Styrke helsetjenestene}

Det er behov for økt kunnskap hos helsepersonell, brukerinvolvering, og styrking av kvalitet og tilgjengelighet til palliativ omsorg og symptomlindring ved livets slutt for eldre (2). Cirka 40 prosent av dødsfallene skjer i sykehjem (4), alle sykehjem må derfor kunne tilby grunnleggende palliasjon til alle pasientgrupper. Ifølge Husebø (24) egner sykehjemmene seg til god omsorg ved livet slutt for gamle, forutsatt at pasientene i livets sluttfase blir møtt med nødvendig kompetanse og ressurser for lindrende behandling. Studier viser at pasientene kan frykte en «dårlig» død og at de fleste er opptatt av å motta god smerte- og symptomlindring (25). Sykehjemmene har bedre forutsetninger for å skape ro rundt den døende enn i sykehus, men utfordringen kan være mangel på palliativ kompetanse hos personalet (26). Dersom pasienten ikke blir godt lindret kan det medføre et press fra pårørende om sykehusinnleggelse.

\section{Brukermedvirkning}

Schaffers (27) norske studie påpeker at dialogen mellom pasient, pårørende og helsepersonell ved palliasjon til eldre må bedres. En annen studie (28) ved to norske sykehjem viser at de fleste pårørende etter dødsfall er fornøyd med omsorgen, men at informasjon og kommunikasjon kan bli bedre. Et fortrinn

\section{Både leger og sykepleiere mangler kunn- skap om symptomlindring og helhetlig behandling ved livets slutt.}

ved langtidsomsorg i kommunene er at personalet kan bli godt kjent med pasientene. Ved å vise interesse for deres livshistorie kan personalet bidra til at pasientenes identitet og verdighet opprettholdes på slutten av livet (29). Ved langtidsomsorg i hjemmet er det også viktig at man samarbeider og kommuniserer med ektefelle og barn eller andre nære familiemedlemmer, og ivaretar deres behov (30).

Palliativ omsorg innebærer å ta hensyn til hele personen, både psykiske, sosiale, kulturelle og åndelige behov (31). En studie fra sykehus (15) om eldres behov ved en palliativ sengepost beskriver psykologiske symptomer knyttet til angst, usikkerhet og lengsel etter «å være hjemme». Flere pasienter var opptatt av at alt er ordnet økonomisk for etterlatte og ønsket å være sammen med partner og barn, mens åndelige behov ikke var så fremtredende. En intervjustudie av pasienter og deres familier, leger og annet helsepersonell (25) viser at det å forberede døden og sørge for en god avslutning på livet er viktige faktorer ved palliativ omsorg. Men hva som er de viktigste faktorene varierer mellom informantene. Studien viser også at pasienter opplever å bli styrket når de får ta del i beslutninger angående palliasjon.

\section{Kommunikasjon}

Det kan være vanskelig for helsepersonell å avgjøre når aktiv behandling skal avsluttes. Det er derfor viktig med gode rutiner og retningslinjer for å innhente informasjon om pasientens ståsted vedrørende livets slutt. Pasientens evne til å ta valg eller formidle egne synspunkter svekkes ofte i sluttfasen av livet.
Kommunikasjon omkring livets slutt bør derfor bli en naturlig del av behandling og pleie i en tidlig fase både i hjemmetjenester og ved sykehjemsopphold $(14,24)$. En studie av eldres oppfatning av døden viser store individuelle variasjoner, og få har kunnskaper om alternativer til livsforlengende behandling (32). Få pasienter ville velge vekk aktiv behandling uten tilstrekkelig kunnskap om alternativer innenfor palliasjon. I omsorg for døende bør derfor åpne, forberedende etiske samtaler mellom pasient, pårørende, lege og pleiepersonell prioriteres, slik at unødig behandling kan unngås (33). Pasientens samtykke er en sentral del av forberedelsene til livets slutt. Der informert samtykke ikke er mulig, blir formodet eller presummert samtykke den sentrale utfordringen. Hva ville pasienten selv ha ønsket i den foreliggende situasjonen (24)? Pårørende kan være en viktig informasjonskilde når pasienter ikke kan redegjøre for egne ønsker (28).

\section{Utdanningstilbud}

Sheehan og Schirm (34) hevder at det er et stort behov for kompetanseheving og kvalitetsforbedring innen omsorg ved livets slutt på sykehjem. I en norsk undersøkelse fra sykehus konkluderes det med at både leger og sykepleiere mangler kunnskap om symptomlindring og helhetlig behandling ved livets slutt (35). Utdanning av både sykepleiepersonell og leger er et viktig virkemiddel for å gjennomføre palliasjon til eldre (6). I Norge har undervisningssykehjemmene i 2004-2007 hatt et prosjekt for forbedring av behandling, pleie og omsorg ved livets slutt. Prosjektet har hatt fokus på kompetanse blant pleiepersonell, undervisning, debrifing etter dødsfall, pårørende, standarder for omsorg og behandling ved livets avslutning, samt ESAS-skjema (36). Videreutdanninger i palliasjon ved høyskoler har gjerne hovedfokus på palliasjon til kreftpasienter. Ved Verdighetssenteret, Bergen Røde Kors sykehjem, er det imidlertid opprettet en utdanning i palliativ omsorg for personell i kommunal eldreomsorg. Utdanningen tar sikte på å lære opp deltakerne i å undervise, for å sikre spredning av kunnskapen på deltakernes arbeidsplass (37). Evalueringen av et lignende utdanningstilbud i USA, «The End-of-Life Nursing Education Consoritum (ELNEC) - Geriatric Training program» (38) viser at 82 prosent av deltakerne fire måneder senere har undervist om palliasjon ved sitt arbeidssted. På den måten bidrar utdanning til å styrke kvaliteten på omsorgen ved livets slutt. Siden eldreomsorgen har høy grad av ufaglært arbeidskraft, kan det synes som om spredning av kunnskapen ved å «lære for å lære videre» er en effektiv fremgangsmåte for å implementere palliasjon i sykehjem og hjemmetjenester. Positiv effekt av undervisningsprogram for ansatte i eldreomsorgen er funnet i en rekke studier, men slike tiltak alene er ikke tilstrekkelig (39). I tillegg til nødvendig kompetanse kreves også godt samspill mellom ulike helseprofesjoner og nivåer i helsetjenestene (4).

\section{Informasjon}

Det bør dessuten satses på kvalitetsforbedringstiltak i praksis og måling av effekter. To oversiktsartikler som oppsummerer kvalitetsindikatorer for palliasjon til skrøpelige eldre $(40,41)$ viser at vurdering av pasientens palliative behov er betydningsfulle faktorer. Det er viktig å nedtegne navn på stedfortreder ved beslutninger og å støtte pårørende. Det er også viktig å avklare målsettinger for palliativ behandling og pleie, samt pasientens preferanser angående symptomlindring og livsforlengende behandling. Denne informasjonen må være tilgjengelig 
ved forflytning mellom omsorgsnivåer. Det er dessuten mulig å få oversikt over de gamles situasjon ved å kartlegge hvilke pasienter som er i livets sluttfase, slik at kommende dødsfall blir mer forutsigbare (42). En studie av langtidsbeboere på institusjon (43) finner at det er avgjørende å avklare når det $\mathrm{i}$ hver enkelt pasients tilfelle er riktig å endre fokus fra aktiv behandling til palliasjon. Studien viser at selv om de fleste pasientene dør med palliativ omsorg, blir palliative tiltak iverksatt sent eller forsinket inntil de siste dagene av livet. Grunnen til dette er ubesluttsomhet eller inaktivitet fra nøkkelpersoner i pasientomsorgen, og at omsorgen blir avbrutt av akutt behandling og sykehusopphold.

\section{Sykepleieforskning}

Hva som er en «god død» er subjektivt påvirket av faktorer som preferanser og erfaringer, sosiodemografi, individets psykiske status, religion og kulturell bakgrunn, samt den sosiale og helsemessige kontekst pasienten befinner seg i $(25,44)$. Det er derfor behov for tverrfaglig forskning på feltet for å unngå at palliasjon overveiende fokuserer på symptomlindring og en mulig patologisering av døden. Det er rimelig å anta at satsning på sykepleieforskning kan bidra til å synliggjøre de psykososiale og åndelige faktorer som er viktige for de gamles livskvalitet på slutten av livet.

\section{Konklusjon}

For å sikre de gamle en verdig slutt på livet må eldreomsorgen tilstrebe at palliasjon inngår i omsorgstilbudet i kommunehelsetjenesten. Med bakgrunn i anbefalinger fra litteraturen bør det være mulig å tilby palliasjon med god kvalitet tilpasset pasientenes behov både i sykehjem og hjemmebaserte tjenester. Viktige satsingsområder er kompetanseheving, standardiserte rutiner for kommunikasjon og symptomlindring, brukermedvirkning og involvering av pårørende. Det samme gjelder tverrfaglig samarbeid i eldreomsorgen og på tvers av tjenestenivåer. Kvalitetsforbedring og sykepleiefaglig forskning vil også bidra positivt.

Både internasjonalt og nasjonalt synes fagfeltet palliasjon å være ledet av miljøer innenfor medisin og særlig innenfor kreftomsorgen. Det er imidlertid svært viktig at sykepleiere med erfaring fra eldreomsorgen bidrar i den videre utviklingen av palliasjon til eldre. Slik kan kunnskapen og ekspertisen som finnes både i det palliative miljøet, på sykehjem og i hjemmesykepleie sammen bidra til et bedret tilbud spesielt rettet mot de gamles behov. Sykepleiere oppfordres til å delta sterkere i oppbygging av fagfeltet, da sykepleie bidrar med viktige kunnskaper som kan supplere det medisinske fagfeltet. Et godt tverrfaglig samarbeid er nødvendig for å sikre en best mulig palliativ omsorg til våre sårbare gamle. IIII

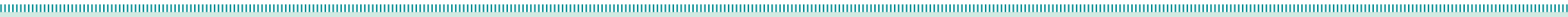

LITTERATUR tralbyrå. Dette er Norge: Et aldrende samfunn. 2008; www.ssb.no/ norge/bef/main (22.09.2008)

2. Davies E, Higginson IJ. Better Palliative Care for Older People. World Health Organization. 2004.

3. Davies E. What are the palliative care needs of older people and how might they be met? WHO Regional Office for Europess Health Evidence Network (HEN). 2004

4. Haugen DF, Jordhøy MS, Engstrand P, Hessling SE, Garåsen H. Organisering av
palliasjon i og utenfor sykehus. Tidsskrift for Den norske lægeforening 2006;126(3): 329-32.

5. Østergaard।, Ottesen SS, Damkier A. Den døende patient. Ugeskrift for Læger 2007;169 (44): 3768-71.

6. Froggatt KA. Palliative care and nursing homes: where next? Palliative Medicine 2001;(15): 42-8.

7. Kaasa S, Haugen DF, Rosland JH. Palliativ medisin - forskning og undervisning et nytt fagfelt. Tidsskrift for Den norske lægeforening 2006;128(3): 333-6.

8. Sørbye LW. Omsorg for døende gjennom 20 år. Tidsskriftet Sykepleien 2000; 19 50-54.

9. Covinsky K, Eng C, Lui L, Sands L, Yaffe K. The Last 2 Years of Life: Functional Trajectories of Frail Older People. Journal of the American Geriatrics Society 2003;51(4): 492-8.

10. Norsk forening for palliativ medisin. Standard for palliasjon. Oslo: Den norske Lægeforening 2004;http://www.legeforeningen.no/asset/24405/2/24405_2. doc (23.07.2008)

11. Amella EJ. Geriatrics and Palliative Care: Collaboration for Quality of Life Until Death. JOURNAL OF HOSPICE AND PALLIATIVENURSING. 2003 January/ March;5(1): 40-8.

12. Lundorff LE, Jensen N-H. Symptomlindring - smerte. Ugeskrift for Læger 2007;169 (44): 3750-2.

13. Ellingsen E, Strand E. Hvordan har du det idag? Tidsskriftet Sykepleien 2007;17:60 64.

14 .Husebø BS, Husebø $\varnothing$. De siste dager og timer - behandling, pleie og omsorg ved livets slutt. Oslo: Medlex Norske Helseinformasjon. 2001.

15. Wijk H, Grimby A. Needs of Elderly Patients in Palliative Care. American Journal of Hospice and Palliative Medicine 2008;25(2): 106-11.

16. Husebø BS. Assessment of Pain in Patients with Dementia. Dissertation for the degree of doctor philosophiae. Universitetet i Bergen, 2008.

17. Mitchell SL, Kiely DK, Hamel MB. Dying With Advanced Dementia in the Nursing Home. Arch Intern Med. 2004;164(3): 321-6.

18. Mowé M. Behandling av underernæring hos eldre pasienter. Tidsskrift for Den norske lægeforening 2002;122(8): 815-8.

19. Lannerstedt H, Mowe M. Når er det indikasjon for PEG og når er det ikke? Omsorg 2007;3:21-6.

20. Husebø S. Avslutte livsforlengend behandling? Bruk eller misbruk av behandling. Omsorg 2006; 4: 39-41.

21. Husebø S. De døende gamle: Retningslinjer for etiske avgjørelser om avslutning av livsforlengende behandlingstiltak. Omsorg 2006;(4): 43-5.

22. Bryon E, de Casterle BD, Gastmans C Nurses) attitudes towards artificial food or fluid administration in patients with dementia and in terminally ill patients: a review of the literature. J Med Ethics 2008;34(6): 431-6.

23. Pasman HRW, Onwuteaka-Philipsen BD, Kriegsman DMW, Ooms ME, Ribbe MW, van der Wal G. Discomfort in Nursing Home Patients With Severe Dementia in Whom Artificial Nutrition and Hydration Is Forgone. Arch Intern Med. 2005;165 (15): 1729-35.

24. Husebø BS, Husebø S. Sykehjemmene som arena for terminal omsorg - hvordan gjør vi deti praksis? Tidsskrift for Den norske Legeforening 2005;125:13524.

25. Steinhauger KE, Christakis NA, Clipp EC, McNeilly M, McIntyre L, Tulsky JA. Factor Considered Important at the End of Life by Patients, Family, Physicians, and Other Care Providers. JAMA 2000;284 (19): 2476-82.

26. Roseland JH, von Hofacker S, Paulsen $\emptyset$. Den døende pasient. Tidsskrift for Den norske lægeforening 2006;126(4): 467-70.

27. Schaffer MA. Ethical problems in endof-life decisions for elderly Norwegians. Nursing Ethics. 2007:14(2): 242-57.

28. Kaarbø E. Omsorg og behandling for sykehjemspasienten i livets sluttfas Rapport delprosjekt: Pårørendes opp- levelser av den omsorg og behandling som ble gitt i livets sluttfase. Bergen: Undervisningssykehjem. 2007.

29. Franklin LL, Ternestedt BM, Nordenfelt L. Views on dignity of elderly nursing home residents. Nursing Ethics 2006;13(2): 130-46.

30. Docherty A, Owens A, Asadi-Lari M Petchey R, Williams J, Carter YH. Knowledge and information needs of informal caregivers in palliative care: a qualitativ systematic review. Palliative Medicine 2008;22(2): 153-71.

31. Kelly K, Ersek M, Virani R, Malloy P, Ferrell B. End-of-life nursing education consortium geriatric training program: Improving palliative care in community geriatric care settings. Journal of Gerontological Nursing 2008;34(5): 28-35.

32. Winter L, Parker B, Schneider M. Imagining the alternatives to life prolongin treatments: Elders) beliefs about the dying experience. Death Studies. 2007;31(7): 619-31.

33. Husebø BS, Husebø S. Etiske avgjørelser ved livets slutt i sykehjem. Tidsskrift for Den norske lægeforening 2004;124 (22): 2926-7.

34. Sheehan DK, Schirm V. End-of-Life Care of Older Adults. AJN. 2003;103 (11): 48-58.

35. Ersland AL, Baranczyk J, Nordstrøm K, Håvåg GS, Bråtveit B. Bedre lindring med tverrfaglighet. Tidsskriftet Sykepleien 2002;20:32-35.

36. Undervisningssykehjem. Omsorg og behandling for sykehiemspasienten ved livets slutt. http://wwwundervisningss ykehjemno/?page_id=258. (nedlastet 07.10.2008).
37. www.verdighetsenteret.no. (nedlastet 19.12.2008)

38. Kelly K, Ersek M, Virani R, Malloy P, Ferrell $B$. End-of-life nursing education consortium geriatric training program: Improving palliative care in community geriatric care settings. Journal of Gerontological Nursing. 2008 May;34(5): 28-35.

39. Froggatt KA, Wilson D, Justice C, MacAdam M, Leibovici K, Kinh J, et al. End-of-life care in long-term care settings for older people: a litteratur review. International Journal of Older People Nursing 2006; (1): 45-50.

40. Lorenz KA, Rosenfeld K, Wenger N. Quality indicators for palliative and endof-life care in vulnerable elders. Journal of the American Geriatrics Society 2007;55:S318-S26.

41. Wenger NS, Rosenfeld K. Quality indicators for end-of-life care in vulnerable elders. Annals of Internal Medicine 2001;135(8): 677-85.

42. Poprock D, Parker Oliver D, Zweig S, Rantz M, Mehr D, Madsen R, et al. Predicting Death in the Nursing Home: Development and Validation of the 6-Month Minimum Data Set Mortality Risk Index. J Gerontol A Biol Sci Med Sci. 2005 April 1, 2005;60(4): 491-8.

43. Travis SS, Loving G, McClanahan L, Bernard M. Hospitalization Patterns and Palliation in the Last Year of Life Among Residents in Long-Term Care. Gerontologist 2001;41(2): 153-60.

44. Hales S, Zimmermann C, Rodin G. The Quality of Dying and Death. Arch Intern Med. 2008;168(9): 912-8. 